\title{
Soroprevalência e fatores associados à infecção por Toxoplasma gondii em caprinos de propriedades rurais do município de Mossoró, $\mathbf{R N}^{1}$
}

\author{
Francisco V.A. Nunes ${ }^{2 *}$, Juliana R. Vaez ${ }^{3}$, Raymundo R. Pinheiro ${ }^{4}$, \\ Antonio C.R. Cavalcante ${ }^{4}$, Ricardo W.A. Vitor ${ }^{5}$ e Silvia M.M. Ahid ${ }^{2}$
}

\begin{abstract}
Nunes F.V.A., Vaez J.R., Pinheiro R.R., Cavalcante A.C.R., Vitor R.W.A. \& Ahid S.M.M. 2013. [Seroprevalence and factors associated with Toxoplasma gondii infection in goats on farms in the municipality of Mossoró, Rio Grande do Norte, Brazil.] Soroprevalência e fatores associados à infecção por Toxoplasma gondii em caprinos de propriedades rurais do município de Mossoró, RN. Pesquisa Veterinária Brasileira 33(5):565570. Departamento de Ciências Animais, Universidade Federal Rural do Semi-Árido, BR 110 Km 47, Mossoró, RN 59625-900, Brazil. E-mail: vitor_farmacia@hotmail.com

The municipality of Mossoró, RN, Northeastern Brazil, is featured on goat rearing. Toxoplasmosis is a zoonosis which is more pathogenic for goats when compared with other animals for slaughter. In this species, the protozoan is often responsible for reproductive problems and economic losses. In order to identify the seroprevalence and risk factors of toxoplasmosis in goats of farms in this municipality, serum samples from 338 animals (320 females and 18 males) of 15 production units were tested by enzyme immunoassay (ELISA). Of the 15 farms, 14 had animals positive for Toxoplasma gondii, and in these the total number of seropositive animals were 125 (123 females and 2 males), yielding a prevalence of $37.0 \%$. There was a significant relationship $(p<0.05)$ between prevalence and sex, and between the prevalence and breed of animals. The most important risk factors associated with T. gondii infection were: water supply with odds ratio $(\mathrm{OR}=2.635)$, containers for water animals located outside the premises of property $(\mathrm{OR}=3.121)$ and the exploitation of dairy type $(\mathrm{OR}=2.546)$. For the analysis of the avidity ELISA, was found females of reproductive age in the acute phase of infection.
\end{abstract}

INDEX TERMS: Toxoplasmosis, Toxoplasma gondii, seroprevalence, goat diseases, ELISA.

RESUMO.- 0 município de Mossoró/RN, no Nordeste do Brasil, tem como destaque a criação de caprinos. A toxoplasmose é uma zoonose que é mais patogênico para os caprinos do que para os demais animais de abate. Em caprinos, o protozoário frequentemente é responsável por problemas reprodutivos e perdas econômicas. Com o ob-

\footnotetext{
${ }^{1}$ Recebido em 11 de setembro de 2012.

Aceito para publicação em 5 de fevereiro de 2013.

${ }^{2}$ Departamento de Ciências Animais, Universidade Federal Rural do Semi-Árido, BR 110 Km 47, Mossoró, RN 59625-900, Brasil. *Autor para correspondência: vitor_farmacia@hotmail.com

${ }^{3}$ Departamento de Ciências Sociais e Agrotecnologia, Universidade Federal Rural do Semi-Árido, BR $110 \mathrm{Km}$ 47, Mossoró, RN.

${ }^{4}$ Embrapa Caprinos, Estrada Sobral-Groaíras, Km 4, Fazenda Três Lagoas, Sobral, CE 62011-970, Brasil.

${ }^{5}$ Instituto de Ciências Biológicas, Departamento de Parasitologia, Universidade Federal de Minas Gerais, Av. Antônio Carlos 6627, Belo Horizonte, MG 31270-901, Brasil.
}

jetivo de identificar a soroprevalência e os fatores de risco da toxoplasmose em caprinos de propriedades rurais do Município de Mossoró, amostras de soro de 338 animais (320 fêmeas e 18 machos) de 15 unidades produtoras foram testados pelo Ensaio Imunoenzimático (ELISA). Das 15 propriedades, 14 apresentaram animais soropositivos para toxoplasmose, e nestas o total de animais positivos foram de 125 (123 fêmeas e 2 machos), obtendo uma prevalência de $37,0 \%$. Houve uma relação significativa $(p<0,05)$ entre a prevalência e o sexo, e entre a prevalência e raça dos animais. As chances de ocorrer (OR) mais importantes associados à infecção por Toxoplasma gondii foram: fonte de água $(\mathrm{OR}=2,635)$, vasilhames para a água dos animais localizado fora das instalações da propriedade $(\mathrm{OR}=3,121)$ e a exploração do tipo leiteira (OR=2,546). Pela análise do ELISA de avidez, foram encontradas fêmeas em idade reprodutiva na fase aguda da infecção. 
TERMOS DE INDEXAÇÃO: Toxoplasmose, Toxoplasma gondii, soroprevâlencia, doenças de caprinos, fatores de risco, ELISA.

\section{INTRODUÇÃO}

A toxoplasmose é uma protozoonose causada pelo agente Toxoplasma gondii que pode parasitar seres humanos e outras espécies de vertebrados (Spalding 2005). É um protozoário de distribuição geográfica mundial, com alta prevalência sorológica, podendo atingir mais de $60 \%$ da população em determinados países, variando de região para região, conforme hábitos socioculturais, fatores geográficos e climáticos (Melo et al. 2007).

A ingestão de carne crua ou mal cozida contendo cistos teciduais é o principal mecanismo de infecção para animais carnívoros e onívoros enquanto a ingestão de oocistos é o principal mecanismo de infecção para herbívoros (Vitor 1992).

A transmissão transplacentaria, por taquizoitos, tem sido responsabilizada pela ocorrência de abortos, natimortos, debilidade e mortalidade neonatal, tanto no homem como em outros animais, sendo essa uma das principais causas de perdas em rebanhos caprinos e ovinos (Dubey et al. 1980, Dubey \& Beattie 1988, Duncanson et al. 2001).

Segundo Dubey et al. (1990) T. gondii é mais patogênico para os caprinos quando comparado aos demais animais de abate. Nesta espécie o protozoário frequentemente causa morte fetal, mumificação, natimortalidade, abortos ou nascimento de animais debilitados, ocasionando perda econômica aos caprinocultores. Sendo considerada uma coccidiose dos felídeos e uma das mais comuns protozoonoses disseminadas em todo o mundo (Hill \& Dubey 2002).

No Brasil, a literatura sobre a toxoplasmose em caprinos ainda é limitada, restringindo-se aos inquéritos sorológicos de alguns estados; frisando a importância desses estudos no Rio Grande do Norte, principalmente no município de Mossoró, o qual a tem como destaque na sua pecuária a criação de rebanhos caprinos. Assim o objetivo desse estudo foi avaliar a soroprevalência da toxoplasmose em caprinos oriundos de propriedades rurais do Município de Mossoró/RN, bem como os fatores de riscos associados à infecção por T. gondii.

\section{MATERIAL E MÉTODOS}

A pesquisa foi realizada em 15 propriedades rurais localizadas nas circunferências do município de Mossoró/RN e que apresentavam a criação de caprinos como animais de produção. A amostragem não probabilística foi utilizada para selecionar os produtores, já que não existia uma listagem representativa dos criadores de caprinos no município, o que tornou impossível uma amostragem ao acaso.

A população estudada constitui-se de uma amostragem estatisticamente calculada. 0 tamanho da amostra foi determinado a partir do número de caprinos estimado pelo Instituto de Defesa e Inspeção Agropecuária do Rio Grande do Norte (IDIARN) de 10.460 animais no município no ano de 2010; utilizando como prevalência esperada um valor de 17,1\% de soropositivos, encontrados no trabalho realizado por Lima et al. (2008), obedecendo o limite sobre o erro de 0,05 obteve-se um total aproximado de 222 animais a serem coletados. Trabalhou-se com soros de 338 animais, ou seja, 116 amostras a mais que o estipulado, desses 320 eram fêmeas e 18 eram machos.
Em cada propriedade $20 \%$ dos animais com mais de um ano de idade foram aleatoriamente amostrados, com exceção de uma única propriedade que possuía apenas 11 animais, sendo a amostra de sangue coletada de todos; e os proprietários entrevistados para obtenção de dados referentes a sexo, raça, manejo, tipo de exploração, fonte de água, presença de gatos, acompanhamento técnico e ocorrência de distúrbios reprodutivos. Os dados epidemiológicos, obtidos pela aplicação de um questionário, e a coleta de sangue foram realizados entre janeiro a maio de 2011 . Foi coletado $5 \mathrm{ml}$ de sangue por de cada animal, centrifugado a $3000 \mathrm{rpm}$ durante 10 minutos para obtenção do soro, que foi aliquotado e estocado a $-20^{\circ} \mathrm{C}$ até o processamento do exame laboratorial.

Nesse estudo o método sorológico utilizado para detectar IgG anti-Toxoplasma gondii foi o Ensaio Imunoenzimático (ELISA), realizado segundo Cavalcante (2004), após padronização previa do método. Paralelamente ao ELISA convencional foi realizado um ELISA para avaliação da avidez de anticorpo IgG para determinar se a infecção presente nos rebanhos foi recente ou crônica.

Os dados foram analisados pelo software estatístico SPSS 17.0 (Statistical Package for the Social Sciences), onde a magnitude da associação dos fatores de risco foi determinada pela razão de chances calculando o "odds ratio" (OR), e a significância foi determinada quando $95 \%$ do intervalo de confiança não incluiu o 1. A análise de associação entre os grupos foi testada pelos métodos estatísticos Qui-Quadrado $\left(\mathrm{X}^{2}\right)$ e exacto de Fisher, com significância estatística determinada se $p$ menor ou igual a 0,05 . As variáveis submetidas a análise Univariada que apresentaram relação com a toxoplasmose com valor de $p<0,20$ e algumas que não apresentaram diferenças significativas, mas que foram consideradas importantes como fator de risco para infecção a toxoplasmose, foram reagrupadas para realização da Regressão Logística Multivariada.

\section{RESULTADOS E DISCUSSÃO}

\section{Soroprevalência da toxoplasmose caprina no Municí- pio de Mossoró, RN}

A escolha do ELISA para este estudo se deve ao fato desta técnica ser considerada sensível, especifica, simples, prática, rápida, de boa reprodutibilidade e de leitura automatizada (Garcia-Vazquez et al. 1993, Silva et al. 2002)

Dentre as 15 propriedades estudadas apenas uma não apresentou nenhum animal positivo, como mostrado no Quadro 1. É interessante observar que houve uma variabilidade da prevalência dependendo da propriedade estudada, com a menor apresentando $7,5 \%$ e a maior $66,7 \%$ de positividade. Dos 338 caprinos selecionados e examinados para a presença de anticorpos anti-Toxoplasma gondii, 125 foram positivos, resultando numa prevalência de 37,0\%.

A prevalência encontrada neste trabalho foi superior a de Cavalcante (2004) que estudou caprinos de diferentes propriedades do estado do Ceará e encontrou uma positividade de $25,1 \%$ de anticorpos anti-T. gondii. Também foi maior que a encontrada por Garcia (2010) e Ragozo (2007) encontrando uma prevalência de 35,95\% e 32,2\%, respectivamente, nos animais estudados. Mostrou-se superior também que a encontrada em Neto (2008), estudando caprinos oriundos da Microrregião do Seridó Oriental do Rio Grande do Norte, encontrou uma soropositividade de $30,6 \%$ para a toxoplasmose. No trabalho de Lima et al. (2008), realizado no município de Mossoró, foi encontrado uma prevalência de $17,1 \%$, resultado inferior encontrado neste estudo. 
Quadro 1. Prevalência de anticorpos anti-Toxoplasma gondii por propriedade analisada no município de Mossoró/RN, pelo ELISA

\begin{tabular}{cccc}
\hline Identificação da & \multicolumn{3}{c}{ Caprinos } \\
\cline { 2 - 4 } propriedade & examinados & Soros positivos & Prevalência (\%) \\
\hline A & 31 & 13 & 41,9 \\
B & 20 & 8 & 40,0 \\
C & 25 & 6 & 24,0 \\
D & 15 & 10 & 66,7 \\
E & 55 & 25 & 45,5 \\
F & 40 & 3 & 7,5 \\
G & 15 & 8 & 53,3 \\
H & 25 & 11 & 44,0 \\
I* & 11 & 6 & 54,5 \\
J & 16 & 10 & 62,5 \\
K & 15 & 4 & 26,7 \\
L & 11 & 0 & 0,0 \\
M & 12 & 6 & 50,0 \\
N & 29 & 9 & 31,0 \\
O & 18 & 6 & 33,3 \\
Total & 338 & 125 & 37,0
\end{tabular}

*Propriedade que teve todos os animais coletados.

Porém a prevalência deste trabalho foi menor que a encontrada por Carneiro (2006) onde foi avaliando 767 soros de caprinos do estado de Minas Gerais encontrando uma positividade em 43\% dos animais; Medeiros (2010) estudando 244 caprinos de propriedades oriundas da mesorregião Central do Estado do Rio Grande do Norte encontrou uma positividade de $47,13 \%$ dos animais estudados; e Silva et al. (2003) estudando rebanhos do estado de Pernambuco encontrou uma prevalência de $40,4 \%$.

Essas diferenças encontradas dentro do mesmo país, estados e até da mesma cidade podem ser devidos a vários fatores que podem influenciar o ciclo epidemiológico da toxoplasmose, como por exemplo: as características dos animais amostrados, as propriedades estudas, o período que o estudo foi realizado, a presença ou não de gatos, diferentes condições climáticas, tipo de manejo, diferentes técnicas sorológicas utilizadas.

Das 320 fêmeas e 18 machos estudados, 38,4 e 11,1\%, respectivamente, foram positivos para toxoplasmose. A analise pelo Qui-Quadrado identificou diferença significativa entre o sexo dos animais (IC 95\% $=0,0452-0,8861$; $\mathrm{p}=0,019$ ), apresentando uma proteção para o sexo masculino (Quadro 2). É importante observar que a quantidade de fêmeas foi muito superior que os machos, fato encontrado nas propriedades estudadas, onde os machos são abatidos ou vendidos e as matrizes são conservadas para finalidade reprodutiva e/ou leite, diminuindo consideravelmente a sua proporção em relação às fêmeas.

Na pesquisa de Garcia (2010) também foi encontrado diferença significativa entre os sexos, verificando que $42,86 \%$ das fêmeas e $23,19 \%$ dos machos foram reagentes para T. gondii. Assim como Silva et al. (2003) onde a porcentagem de fêmeas sororregentes foi significativamente maior que a de machos, com $43,88 \%$ contra $21,21 \%$, respectivamente.

Já Ragozo (2007), apesar de ter obtido uma maior proporção de fêmeas positivas, não encontrou associação da positividade na sorologia com o sexo do animal, sendo das
Quadro 2. Distribuição dos casos positivos $(n=125)$ para toxoplasmose, de acordo com as características das propriedades com respectivos valores absolutos e relativos

\begin{tabular}{|c|c|c|c|c|c|}
\hline Variáveis & $\mathrm{n}$ & $\%$ & $\begin{array}{c}\text { Chances } \\
\text { de ocorrer } \\
(\mathrm{OR})\end{array}$ & IC- 95\% & $\begin{array}{l}\text { Valor } \\
\text { de p }\end{array}$ \\
\hline \multicolumn{6}{|l|}{ Animais/sexo } \\
\hline Machos & 2 & 1,6 & 0,200 & $0,0452-0,8861$ & 0,019 \\
\hline Fêmeas & 123 & 98.4 & & & \\
\hline \multicolumn{6}{|l|}{ Exploração } \\
\hline Corte* & 81 & 64,8 & 1 & - & - \\
\hline Leiteira & 20 & 16,0 & 0,567 & $0,307-1,05$ & 0,072 \\
\hline Mista & 24 & 19,2 & 1,688 & $0,834-3,412$ & 0,143 \\
\hline \multicolumn{6}{|l|}{ Alimentação } \\
\hline Pasto/Ração* & 50 & 40 & 1 & - & - \\
\hline Pasto & 65 & 52 & 1,206 & $0,760-1,915$ & 0,427 \\
\hline Ração & 10 & 8 & 0,3086 & $0,100-0,955$ & 0,034 \\
\hline \multicolumn{6}{|l|}{ Manejo } \\
\hline Confinada* & 10 & 8 & 1 & - & - \\
\hline Semi-intensiva & 87 & 69.6 & 2,966 & $0,980-8,975$ & 0,045 \\
\hline Extensiva & 28 & 22,4 & 5,643 & $1,774-17,943$ & $<0,01$ \\
\hline \multicolumn{6}{|l|}{ Fonte de água } \\
\hline Adutora & 60 & 52 & 1,147 & $0,736-1,785$ & 0,545 \\
\hline Poço Artesiano & 65 & 48 & & & \\
\hline \multicolumn{6}{|c|}{ Local de oferecimento de água } \\
\hline $\begin{array}{l}\text { Vasilhame dentro das ins- } \\
\text { talações }\end{array}$ & 100 & 80 & 1,525 & $0,850-2,735$ & 0,154 \\
\hline $\begin{array}{l}\text { Vasilhame fora das ins- } \\
\text { talações }\end{array}$ & 25 & 20 & & & \\
\hline \multicolumn{6}{|c|}{ Contato com animais de outras propriedades } \\
\hline Sim & 35 & 28 & 0,866 & $0,5324-1,409$ & 0,562 \\
\hline Não & 90 & 72 & & & \\
\hline \multicolumn{6}{|l|}{ Problemas reprodutivos } \\
\hline Sim & 81 & 64,8 & 0,7219 & $0,4497-1,159$ & 0,176 \\
\hline Não & 44 & 35,2 & & & \\
\hline \multicolumn{6}{|c|}{ Criação de gatos na propriedade } \\
\hline Sim & 68 & 54,4 & 1,482 & $0,950-2,310$ & 0,08 \\
\hline Não & 57 & 45,6 & & & \\
\hline \multicolumn{6}{|l|}{ Gatos selvagens } \\
\hline Sim & 4 & 3,2 & 0,336 & $0,193-0,585$ & 0,001 \\
\hline Não & 121 & 96,8 & & & \\
\hline \multicolumn{6}{|c|}{ Acesso de gatos aos locais dos animais } \\
\hline Sim & 115 & 92 & 0,276 & $0,092-0,828$ & 0,015 \\
\hline Não & 10 & 8 & & & \\
\hline \multicolumn{6}{|c|}{ Acesso de gatos a água dos animais } \\
\hline Sim & 63 & 50,4 & 0,7435 & $0,477-1,159$ & 0,19 \\
\hline Não & 62 & 49,6 & & & \\
\hline \multicolumn{6}{|c|}{ Presença de animais silvestres } \\
\hline Sim & 69 & 55,2 & 0,629 & $0,400-0,989$ & 0,044 \\
\hline Não & 56 & 44,8 & & & \\
\hline \multicolumn{6}{|l|}{ Abatem animais } \\
\hline Sim & 112 & 89,6 & 0,795 & $0,376-1,684$ & 0,549 \\
\hline Não & 13 & 10,4 & & & \\
\hline \multicolumn{6}{|l|}{ Contato de gatos } \\
\hline Sim & 99 & 79,2 & 2,154 & $1,102-4,210$ & 0,023 \\
\hline Não & 13 & 10,4 & & & \\
\hline \multicolumn{6}{|l|}{ Local do abate } \\
\hline Descampado* & 10 & 8 & 1 & - & - \\
\hline Pátio & 84 & 67,2 & 3,512 & $1,235-9,985$ & 0,013 \\
\hline $\begin{array}{l}\text { Local fechado, outras ati- } \\
\text { vidades }\end{array}$ & 18 & 14,4 & 1,111 & $0,319-3,871$ & 0,869 \\
\hline \multicolumn{6}{|l|}{ Acompanhamento técnico } \\
\hline Sim & 41 & 32,8 & 0,735 & $0,462-1,168$ & 0,192 \\
\hline Não & 84 & 67,2 & & & \\
\hline Raça & & & & & \\
\hline Pura & 29 & 23,2 & 1,917 & $1,083-3,392$ & 0,024 \\
\hline SRD & 96 & 76,8 & & & \\
\hline
\end{tabular}

$\overline{* \text { Categoria de referencia. OR }}=$ Chances de ocorrer, IC-95 = Intervalo de confiança de $95 \%$. 
52 fêmeas e dos 91 machos, 18 (34,6\%) e 28 (30,8\%), respectivamente, apresentaram anticorpos anti-T. gondii.

Medeiros (2010) também não encontrou diferença significativa entre a positividade e o sexo, porém a proporção de fêmeas foi superior que a de machos, representando $92,2 \%$ e 7,8\%, respectivamente, dos 115 animais reativos, e $43,4 \%$ e $3,7 \%$, respectivamente, do total de 244 animais estudados.

Cavalcante (2004), Carneiro (2006) e Lima et al. (2008) também não encontraram diferença significativa entre o sexo dos animais.

O papel do sexo na proporção de animais sororreagentes pode estar relacionado a fatores secundários, envolvendo diferentes eventos fisiológicos, relacionados ao processo reprodutivo desses animais (ovulação, prenhez, lactação), onde se encontram envolvidos aspectos hormonais. É possível ainda que o manejo empregado para reprodutores e matrizes também possa ter influenciado estes resultados (Cavalcante 2004).

Quanto à raça dos caprinos, a proporção de animais apresentando anticorpos anti-T. gondii mostrou que a prevalência deste protozoário foi significativamente diferente entre as duas categorias raciais analisadas $(p<0,05)$. Os animais de raça pura apresentaram maior proporção de positividade para a toxoplasmose $(50 \%)$ quando comparado com os animais sem raça definida (SRD) (IC $=1,083$ 3,392; $\mathrm{p}=0,024$ ).

Este trabalho corrobora com Ragozo (2007) que observou uma associação de positividade entre animais de raça pura (46,2\%). Assim como Carneiro (2006), onde o autor encontrou diferença significativa entre as categorias raciais, sendo os animais de raça pura aqueles que apresentaram maior soropositividade para anticorpos anti-T. gondii (46,3\%). Já no estudo de Cavalcante (2004) e Medeiros (2010) não demonstraram diferença estatística significativa entre a raça dos animais.

Apesar desse estudo não ter avaliado a soroprevalência dos animais em relação a idade, inúmeros trabalhos têm demonstrado uma grande relação da positividade com o aumento da idade dos animais. Os animais com idades maiores têm apresentado índices de reatividades superiores que animais mais jovens, ou seja, quanto maior a idade dos caprinos mais frequente a presença de anticorpos anti- T. gondii (Cavalcante 2004, Carneiro 2006, Ragozo 2007, Garcia 2010, Medeiros 2010).

\section{Chances de ocorrer a toxoplasmose caprina no municí-} pio de Mossoró, RN

Como mostrado no Quadro 3, os fatores de risco identificados nas unidades produtoras de caprinos de Mossoró

Quadro 3. Variáveis que oferecem risco para a infecção por Toxoplasma gondii de acordo com a regressão logística multivariada

\begin{tabular}{lccc}
\hline \multicolumn{1}{c}{ Variável } & OR & IC-95\% & $\mathrm{p}$ \\
\hline Local do vasilhame & 3,121 & $1,148-8,484$ & 0,026 \\
Fonte de água & 2,635 & $1,091-6,363$ & 0,031 \\
Exploração & 2,546 & $1,396-4,641$ & $<0,01$
\end{tabular}

OR = Chances de ocorrer. para a infecção por T. gondii a partir da regressão logística multivariada foram: fonte de água, localização dos vasilhames e exploração.

A análise da regressão logística multivariada mostrou que a adutora como fonte da água oferecida aos caprinos mostrou risco aumentado em 2,6 para infecção da toxoplasmose (OR=2,635; IC 95\% =1,091-6,363; $\mathrm{p}=0,031)$. Assim como a localização dos vasilhames onde a água é oferecida aos animais. Os vasilhames localizados fora das instalações da propriedade apresentou risco aumentado em 3,1 vezes (OR=3,121; IC 95\% =1,148-8,484; $p=0,026)$ para a infecção por T. gondii.

Isto pode está relacionado aos aspectos de higienização da água oferecida aos animais, tanto na sua origem, quanto no local onde é oferecido, pois dificilmente essa água passa por algum tipo de tratamento antes de ser ofertada aos caprinos, além de os vasilhames onde ela fica armazenada não serem limpos com freqüência.

Os vasilhames que estão localizados fora das instalações da propriedade, por conseqüência, apresentam maior facilidade aos gatos terem acesso a água que é ofertada aos caprinos, principalmente os gatos errantes. Esse acesso pode facilitar a contaminação por oocistos do parasita, favorecendo a infecção dos animais e a manutenção da cadeia epidemiológica da toxoplasmose.

A presença de gatos não se mostrou como um fator de risco pela regressão logística multivariada, apresentando apenas uma relação significativa na análise univariada, com a chance de ocorrer bruta (OR=1,482; IC $95 \%=0,950$ 2,$310 ; p=0,08$ ). Foi observado que $53,3 \%$ das propriedades criavam gatos, porém todos os produtores relataram que a presença de gatos errantes era comum nas circunferências das unidades produtoras, onde $93,3 \%$ afirmaram que esses animais tinham acesso ao pasto dos caprinos.

A criação ou presença de gatos pode ser um risco em potencial para a disseminação da doença para outras espécies de animais. Os felídeos são fundamentais na transmissão da toxoplasmose, sendo os únicos hospedeiros da forma sexuada e definitiva do parasita. Por eliminarem oocistos nas fezes os felinos são a única fonte de infecção dos animais herbívoros. A estreita relação dos gatos, domésticos ou errantes, através de excreções e secreções, pode ser um risco na transmissão da toxoplasmose aos animais de produção.

Neto et al. (2008) e Garcia (2010) encontraram uma associação significativa entre a soroprevalência de anti-T. gondii e presença de gatos em rebanhos caprinos. Cavalcante (2004) encontrou que há uma associação entre a prevalência da toxoplasmose em caprinos com o aumento no número de gatos nas propriedades. A presença de gatos errantes também pode ser um fator extremamente importante para a manutenção da cadeia epidemiológica da toxoplasmose, já que esses animais costumam caçar, infectando-se mais que gatos de estimação que são tratados com ração (Vargas 2006). Todos esses trabalhos indicando que a presença de gatos e o contato próximo com esta espécie é importante na epidemiologia da infecção.

No presente trabalho foi encontrado resultado significativo para a infecção e os animais do tipo leiteiro, com risco 
de 2,5 a mais de se infectar por T. gondii (OR=2,546; IC 95\% $=1,396-4,641 ; \mathrm{p}<0,01)$ que outros sistemas de exploração.

0 resultado encontrado corrobora com o trabalho de Silva (2003), que encontrou prevalência significativamente maior de infecção por T. gondii em rebanhos leiteiros

Garcia (2010), apesar de não ter estudado propriedades exclusivamente leiterias, encontrou uma maior prevalência da toxoplasmose em caprinos de propriedades de exploração mista (carne e leite) quando comparados com animais criados para abate.

Nas propriedades leiteiras os animais se mantêm por mais tempo concentrados e em maior contato com alimentos e água possivelmente contaminados por oocistos, além de que, nessas propriedades a media de idade dos animais é maior e, consequentemente, suas chances de contato com os oocistos também aumentam (Garcia 2010).

Jittapalapong et al. (2005) levantam a hipótese de que caprinos leiteiros têm maior chance de contrair os oocistos de T. gondii que caprinos de corte devido ao manejo e ao tipo racial exigido para cada grupo. Os animais destinados a produção de leite, geralmente são de raça pura, sendo assim, mais susceptível a infecção.

\section{Análise da avidez de anticorpo da classe IgG anti-Toxo- plasma gondii}

Na fase inicial das infecções por T. gondii, uma alta percentagem de anticorpos IgG mostra baixa avidez para os antígenos correspondentes. Decorrido esse período, que pode ser de semanas ou meses, esses anticorpos vão apresentando avidez crescente, de modo que em infecções crônicas, são detectados anticorpos de alta avidez (Camargo et al. 1991).

São pouco os trabalhos que procuram diferenciar o tipo de infecção (aguda e crônica) que está acometendo os rebanhos caprinos no Brasil, neste estudo, dos 125 soros analisados, $118(94,4 \%)$ tiveram anticorpos IgG de alta avidez e $7(5,6 \%)$, anticorpos de baixa avidez. Os resultados assinalam que a maioria dos soros avaliados tinham anticorpos de alta avidez, indicando nesses rebanhos que considerável percentual de animais eram portadores de infecção crônica. Bahia et al. (1995), observaram que caprinos infectados experimentalmente com $T$. gondii, tiveram predomínio de anticorpos IgG de baixa avidez até o 100 dpi (dias após infecção).

A análise de avidez no estudo de Medeiros (2010) foi realizada nos soros de 115 caprinos reativos pelo ELISA convencional. Destes, $103(89,6 \%)$ soros apresentaram anticorpos IgG de alta avidez, indicando infecção crônica, e 12 $(10,4 \%)$ possuíam anticorpos IgG de baixa avidez, indicando infecção aguda.

No trabalho de Carneiro (2006) 73,2\% dos animais positivos pelo ELISA possuíam anticorpos de alta avidez e $26,8 \%$ anticorpos de baixa avidez, indicando que a maioria dos animais estudados provavelmente estava na fase crônica da doença. 0 autor não encontrou associação da avidez de anticorpos com as variáveis individuais dos animais como sexo, raça e idade.

Nesse estudou houve um predomínio de fêmeas com anticorpos tanto de baixa quanto de alta avidez, 85,7\% e
99,2\% respectivamente, indicando maior proporção de fêmeas tanto para infecção aguda como crônica. Isso pode sugerir que o manejo, como a exploração podem estar influenciando a avidez nos sexos dos animais.

Medeiros (2010) encontrou uma associação estatisticamente significativa quando relacionado a avidez do anticorpo com o sexo do animal, onde as fêmeas apresentaram elevados percentuais de anticorpos IgG de alta avidez quando comparados com os machos.

Quanto a raça dos animais, todos os que apresentavam anticorpos de baixa avidez estavam no grupo dos SRD, mostrando maior susceptibilidade desses animais a desenvolverem infecção aguda por T. gondii.

Apesar de Medeiros (2010) não ter identificado diferença estatística significativa, na comparação da raça com a avidez dos animais, encontrou que os animais de raça pura apresentam maiores percentuais de anticorpos de alta avidez $(77,4 \%)$ do que os animais sem raça definida $(12,2 \%)$, o que diverge nos resultados encontrados neste trabalho.

\section{CONCLUSÕES}

A elevada proporção de animais positivos nos diferentes rebanhos caprinos estudados neste levantamento indica que Toxoplasma gondii encontra-se amplamente difundido entre pequenos ruminantes no município de Mossoró, Rio Grande do Norte.

Houve uma relação significativa $(\mathrm{p}<0,05)$ entre a prevalência e o sexo, e entre a prevalência e raça dos animais, mostrando maior proporção da infecção por T. gondii em fêmeas do que em machos, e nos animais de raça pura, quando comparados com os SRD.

O elevado número de fêmeas positivas pode favorecer a transmissão vertical entre matriz e cria, aumentando o risco de problemas reprodutivos e perdas econômicas.

Os fatores de risco mais importantes associados à infecção por T. gondii foram: fonte de água oriunda de adutora, vasilhames para a água dos animais localizados fora das instalações da propriedade e a exploração do tipo leiteira.

Como todos os animais coletados apresentavam idade superior a 12 meses, sendo a maioria dos positivos para anticorpos de baixa avidez do sexo feminino; a associação aponta para a ocorrência de fêmeas em idade reprodutiva, em fase aguda da toxoplasmose. Esta ocorrência permite casos de transmissão congênita do parasito, com possibilidades de perdas por abortos ou malformação fetal.

\section{REFERÊNCIAS}

Bahia M.T., Vitor R.W.A., Caldas R.P., Antunes C.M.F. \& Chiari C. de A. 1995. Avidez de anticorpos específicos anti-Toxoplasma da classe IgG e sua utilização na diferenciação entre toxoplasmose recente e crônica em caprinos. Bras. J. Vet. Anim. Sci. 32:11-16.

Camargo M.E., Silva S.M., Leser P.G. \& Granato G.H. 1991. Avidez de anticorpos IgG específicos como marcador de infecção primária recente pelo Toxoplasma gondii . Revta Inst. Med. Trop., São Paulo, 33:213-218.

Carneiro A.C.A.V. 2006. Soroepidemiologia da toxoplasmose caprina e ovina no Estado de Minas Gerais. Dissertação de Mestrado em Parasitologia, Instituto de Ciências Biológicas, Universidade Federal de Minas Gerais, Belo Horizonte, MG. 116p.

Cavalcante A.C.R. 2004. Epidemiologia e caracterização de Toxoplasma gondii (Nicolle etManceaux, 1909) em Caprinos no Ceará. Tese de Dou- 
torado em Parasitologia, Instituto de Ciências Biológicas, Universidade Federal de Minas Gerais, Belo Horizonte, MG. 145 p.

Dubey J.P., Sharma P., Lopes C.W.G., Williams J.F., Williams C.S.F. \& Weisbrode S.E. 1980. Caprine toxoplasmosis: abortion, clinical signs, and distribution of Toxoplasma in tissues of goats fed Toxoplasma gondii oocysts. Am. J. Vet. Res. 41(7):1072-1076.

Dubey J.P. \& Beattie C.P. 1988. Toxoplasmosis of Animal and Man. CRC Press, Boca Raton. 220p.

Dubey J.P., Kotula A.W., Sharar A., Andrews C.D. \& Lindsay D.S. 1990. Effect of high temperature on infectivity of Toxoplasma gondii tissue cysts in pork. J. Parasitol. 76(2):201-204.

Duncanson P., Terry R.S., Smith J.E. \& Hide G. 2001. High levels of congenital transmission of Toxoplasma gondii in a commercial sheep flock. Int. J. Parasitol. 31:1699-1703.

Garcia G. 2010. Soroepidemiologia da toxoplasmose caprina na Mesorregião Metropolitana de Curitiba, Paraná, Brasil. Dissertação de Mestrado em Microbiologia, Parasitologia e Patologia, Setor de Ciências Biológicas e da Saúde, Universidade Federal do Paraná, Curitiba, PR. 122p.

García-Vázquez Z., Rosario-Crus R., Díaz García G. \& Hernández-Baumgarten 0.1993. Seroprevalence of Toxoplasma gondii in cattle, swine and goats in four Mexican states. Prev. Vet. Med. 17(1):127-132.

Hill D. \& Dubey J.P. 2002. Toxoplasma gondii: transmission, diagnosis and prevention. Clin. Microbiol. Infect. 8:634-640.

Jittapalapong S., Sangvaranond A., Pinyopanuwat N., Chimnoi W., Khachaerm W., Koizumi S. \& Maruyama S. 2005. Seroprevalence of Toxoplasma gondii infeccion in domestic goats in Satun Province, Thailand. Vet. Parasitol. 127:17-22.

Lima J.T.R., Ahid S.M.M., Barreto Junior R.A., Pena H.F.J., Dias R.A. \& Gennari S.M. 2008. Prevalência de anticorpos anti-Toxoplasma gondii e anti-Neospora caninum em rebanhos caprinos do Município de Mossoró, Rio Grande do Norte. Braz. J. Vet. Res. Anim. Sci. 45:81-86.

Medeiros A.D. 2010. Ocorrência da infecção por Toxoplasma gondii e avaliação da imunização em caprinos do Sertão do Cabugi, Rio Grande do Norte. Dissertação de Mestrado em Ciências Biológicas, Centro de
Biociências, Universidade Federal do Rio Grande do Norte, Natal, RN. 94p.

Melo A.L., Linardi P.M. \& Vitor R.W.A. 2007. Parasitologia Humana. 11ํㅡㄹ. Atheneu, São Paulo, p.163-179.

Miller C.M., Boulter N.R., Ikin R.J. \& Smith N.C. 2009. The immunobiology of the innate response to Toxoplasma gondii. Int. J. Parasitol. 39:23-39.

Neto J.O., Azevedo S.S., Gennari S.M., Funada M.R., Pena H.F., Araújo A.R., Batista C.S., Silva M.L., Gomes A.A., Piatti R.M. \& Alvez C.J. 2008. Prevalence and risk factors for anti-Toxoplasma gondii antibodies in goats of the Seridó Oriental microregion, Rio Grande do Norte state, Northeast region of Brazil. Vet. Parasitol. 156:329-332.

Ragozo A.M.A. 2007. Isolamento e caracterização biológica e genotípica de Toxoplasma gondii de ovinos e caprinos. Tese de Doutorado em Epidemiologia Experimental e Aplicada às Zoonoses, Faculdade de Medicina Veterinária e Zootécnica, Universidade de São Paulo, São Paulo, SP. 144 p.

Silva A.V., Cunha E.L.P., Meireles L.R., Gottscalk S., Mota R.A. \& Langoni H. 2003. Toxoplasmose em ovinos e caprinos: estudos soroepidemiológicos em duas regiões do Estado de Pernambuco, Brasil. Ciência Rural 33:115-119.

Silva A.V., Cutolo A.A. \& Langoni H. 2002. Comparação da reação de Imunofluorescência Indireta e Método de Aglutinação Direta na detecção de anticorpos anti-Toxoplasma gondii em soros de ovinos, caprinos, caninos e felinos. Arqs Inst. Biológico, São Paulo, 69:2-11.

Spalding S.M., Amendoeira M.R.R., Klein C.H. \& Ribeiro L.C. 2005. Serological screening and toxoplasmosis exposure factors among pregnant women in South of Brazil. Revta Soc. Bras. Med. Trop. 38:173-177.

Vargas C.S.G. 2006. Títulos de anticorpo da classe IgG anti-Toxoplasma gondii (Nicolle et Manceaux, 1908) e de oocistos em fezes de gatos de rua (Felis catus Linnaeus, 1758) em Curitiba, Paraná. Dissertação de Mestrado em Ciências Veterinárias, Setor de Ciências Agrárias, Universidade Federal do Paraná, Curitiba, PR. 66p.

Vitor R.W.A. 1992. Infecção experimental de caprinos por Toxoplasma gondii. Tese de Doutorado em Parasitologia, Instituto de Ciências Biológicas, Universidade Federal de Minas Gerais, Belo Horizonte. 176p. 